\title{
Work Meaning Patterns in Early Career
}

\author{
Rita Claes ${ }^{12}$ \\ University Gent \\ Department of Sociopsychology of Work and Organization \\ University Gent \\ Henri Dunantlaan 2 \\ 9000 Gent, Belgium \\ and \\ S. Antonio Ruiz Quintanilla \\ Center for Advanced Human Resource Studies \\ New York State School of Industrial and Labor Relations \\ Cornell University \\ Ithaca, NY 14853-3901
}

Working Paper \#93-22

Article accepted for publication in the EUROPEAN WORK AND ORGANIZATIONAL PSYCHOLOGIST.

This paper has not undergone formal review or approval of the faculty of the ILR School. It is intended to make results of Center research, conferences, and projects available to others interested in human resource management in preliminary form to encourage discussion and suggestions. 


\begin{abstract}
Work meaning patterns combine dimensions such as work centrality, expressive versus economic work goals, entitlement versus obligation societal norms into a holistic picture of the over time evolution of the meaning of work. Data from a longitudinal study in eight European countries are used to empirically establish major work meaning patterns and to study their stability during the early career. Further, some potential determinants of these work meaning patterns are analyzed and their consequences for the later career are considered. Statistical analyses include: cluster analysis, multiple discriminant analysis, analysis of covariance combined with multiple classification analysis, analysis of variance, and chi square analysis. Five cross-national work meaning patterns are identified for machine operators in their third year of labour market participation. One third of the sample remain in the same work meaning pattern over a time period of two years, while two third change their pattern membership. Respondents' age, country, prior work environment, and their prior work socialization behaviours and outcomes have an impact on work meanings held two years later. In addition the work meaning pattern shared by the respondent allows to predict subsequent career enhancing strategies and effort expenditure at the job.
\end{abstract}

\title{
Property of
}

RARTIN P. CATHERWOOD LBSAAC

NEW YORR STATE SEHBOL

INDUSTRIAL ANO LABOR RELATOUIS.

Cornell IInivarsity 


\section{Work Meaning Patterns in Early Career}

The present article uses an approach to the study of the work socialization process (WOSY International Research Group, 1989a, 1992), which sees work meanings at the core of the dynamic and reciprocal interaction between the person and the work environment. Essential for this view is that single work meaning dimensions are not conceptualized as operating independently, but rather that they form a coherent and meaningful pattern reflecting the relationships among the dimensions. Empirically derived work meaning patterns enable us to ponder meanings assigned to working in a more comprehensive way compared to single dimension approaches. Work meaning patterns are operationalized as combinations of individuals' scores on the major work meaning dimensions empirically found by earlier research (MOW International Research Team, 1987): work centrality, work goals, and societal norms about working.

The occurrence of these work meaning patterns is embedded in the specific country's labour market aspects and governmental policies addressed towards young workers. Determinants of work meaning patterns (Nord, Brief, Atieh \& Doherty, 1987; O’Brien, 1992; Shapira \& Griffith, 1990) may be the early work environment (such as organizational quality, occupational situation), the early work outcomes and behaviours, as well as personal characteristics of the youngsters. Indeed, pursuing further the interactive approach, the outcomes (such as psychological well-being) and subsequent behaviours (such as enhancing behaviours) at an early stage of work socialization, feedback to the person-environmental fit, and consequently can alter the work meanings and the 
broader work motivation at a later stage (Kanfer, 1992). Consequences of work meaning patterns (Brief, 1991) may show up in the individual's work socialization outcomes and his/her accommodation behaviours, which in turn can influence organizational policies towards young workers (Leibowitz, Schlossberg \& Shore, 1992) and can have societal implicaiions (Aston, Maguire \& Spilsbury, 1990).

The cross-national comparative component of the study with data from eight countries allows to describe the dynamics of work meanings in different national and cultural settings, and to better understand country-specific work meanings; study the impact of macro variables (such as various educational systems) (Ruiz Quintanilla, 1991); validate cross-nationally a pattern-oriented research strategy by addressing problems such as the similarity of patterns across countries; and exploring the similarity of developmental implications of a given pattern regardless of the country in which they are observed (Gustafson \& Magnusson, 1991). The international scope of the research gains relevance in the context of the unified internal European market, operative from 1 Novemter 1993 (Council of the European Communities, 1992).

In addition the longitudinal design of the research enables us to analyze the stability and developmental process of work meaning patterns to clarify both their sources and outcomes.

This paper considers three components of the interactional person-environment process during early work socialization.

First, the person related aspects are empirically established by identifying major work meaning 
patterns. The research questions addressed here are: What empirical work meaning patterns can be identified ? Are the work meaning patterns relatively stable components of the "work personality" as assessed over a time period of two years or are the patterns more situation dependent (Kanungo, 1991; O’Brien, 1992) ?

Than, the person-environment component is explored by analyzing potential determinants as they relate to work meanings. The research questions here are: Are the empirically identified work meaning patterns country specific or general in nature? To what extent, if at all, does early work environment and work behaviour influence the formation of work meaning patterns ? What is the relative impact of various determinants of work meaning patterns ?

Finally, conceivable consequences of work meaning patterns are considered. The research questions here are: To what extent, if at all, are work meaning patterns predictors for work behaviour such as effort on the job ? What work related processes and important outcomes (such as career enhancing behaviour, psychological well-being) can be explained by differences in work meaniilg pattern membership ?

\section{Method}

\section{Procedure}

Data were gathered through interviews at each of three measurement points during which a questionnaire was administered (WOSY International Research Group, 1989b): T1 (1988-89) was standardized over countries as being employed in the first full-time, fully paid job for a period of 
9-12 months; T2 (1989-90) was about one year later than T1, and T3 (1990-91) was again about one year later than $T 2$. The present paper analyzes data gathered at $\mathrm{T} 1$ and at $\mathrm{T} 3$, thus covering the first three years of labour market participation.

Samples

Under study are machine operators in production/manufacturing departments in the metal industry, for example: die casting machine operators, machine moulders, lathe and milling machine operators, machine coremakers, machine tool fitter-assemblers, welders, machine flame-cutter operators. Analyzed are data from 629 machine operators in eight countries (Belgium 15.7\%, France 1.1\%, England $23.2 \%$, Israel 11.8\%, Italy $13.4 \%$, Netherlands $12.6 \%$, Portugal $6.0 \%$, Spain $16.2 \%$ ). Respondents are $95.9 \%$ males, $88.5 \%$ have reached a secondary school diploma as highest education at $\mathrm{T} 1$. The mean age at $\mathrm{T} 1$ is 20.6 years.

\section{Measures}

Five work meaning indices are constructed to cover the core components of meaning of working (MOW International Research Team, 1987): work centrality, work goals, and societal norms about working.

Work centrality is defined as the degree of general importance that working has in the life of an individual at any given point in time. The work centrality index stems from the responses to an absolute rating of work centrality where respondents rate work on a 7-point scale, and to a relative work centrality question where respondents allocate 100 points between five areas in life (leisure, 
community, work, religion, family) to reflect their relative importance.

Work goals are defined as the relative importance of eleven work goals and values sought by individuals in their working lives. Responses to two set of goals were averaged to form the indices. The economic index includes the importance of good job security, promotion opportunities and good pay at work. The expressive index reflects the importance of interesting work, variety, and autonomy as work goals.

Societal norms about working address rights and duties toward working. The extent of agreement with three duties (contribute to society by working; save portion of regular income for future; value the work you do even if it's boring, dirty, or unskilled) was averaged to obtain a score on the obligation index. The extent of agreement with four rights (retraining and reemployment if skills become outdated, participation in decisions of work methods, general right to interesting and meaningful work, general right to work) was averaged to obtain a score on the entitlement index. The T1-T2 retest stabilities and the T2-T3 retest stabilities of the work meaning indices are significant beyond the .001 level.

The measures on work environment, work socialization outcomes and subsequent behaviours are described in detail in WOSY International Research Team (1989b, 1992). Here we just give a short overview. From the multidomain work environment we study the external labour market outlook, the organizational quality in terms of job progress and experiences with co-workers, and the functional properties of the jobs the youngsters hold indicating whether the jobs mainly deal with 
data, or people, or things through an adaptation of the functional job analysis method (Fine \& Wiley, 1971). Work socialization outcomes include youth person-environment (mis)match, the eventual role conflict and ambiguity, the psychological well-being and satisfaction. Career enhancing behaviours and the level of effort put into work as compared to co-workers are addressed as subsequent work socialization behaviours.

\section{Results}

\section{Work meaning patterns at T3}

To empirically identify major work meaning patterns, Ward's method of hierarchical agglomerative clustering (Ward, 1963; Wishart, 1987) is conducted on 629 respondents' z-scores on the $\mathrm{T} 3$ work meaning indices.

Considering the optimal ratio between loss of variance and the number of clusters, the evolution of the number of respondents in each cluster, and the stability of the cluster solution regardless of order of cases, the optimal solution identifies five clusters. Examination of the cluster diagnostic statistics F- and T-ratio indicate that all five work meaning indices can serve as cluster indicators identifying the relatively unique and homogeneous content of each cluster. Table 1 gives for each index (as measured at T3) the mean and the standard deviation per cluster/pattern and overall. 
Labels for the work meaning patterns are derived through examination of the means on the work meaning indices and their composing items, and by comparison with earlier research (MOW International Research Team, 1987; England \& Ruiz Quintanilla, 1989; England \& Whitely, 1990; Ruiz Quintanilla, 1990). A further brief characterization of the patterns is given by studying the patterns' means on related meaning of working questions (MOW International Research Team, 1987) concerning on the one hand the valued working outcomes (status and prestige, income, contact, society service, intrinsic value of the work itself), and on the other hand the patterns' percentages of the work definitions chosen from a list of fourteen activities.

Pattern $1(\mathrm{~N}=209,33.2 \%)$ : Members of this pattern are moderately work centred, non-economic, and put low emphasis on the entitlement dimension. They value the society serving function of work and attach a high importance to good interpersonal relations at work. Finally, comfort aspects like working conditions and convenient work hours are seen as rather unimportant. Pattern 1 is labelled further as "moderately work centred, non-economic, low rights workers".

Pattern $2(\mathrm{~N}=111,17.6 \%)$ : This group can be called "non-work centied, high expressive and economic work goals, non-duty workers". They highly value expressive work goals, especially a good match individual abilities/job requirements, but as well economic work goals like promotion and pay. Also comfort aspects of work are seen as important. Seen as rather unimportant are status and prestige aspects of work. Compared to the other patterns they more often define work as unpleasant, and something one has to do and less often as serving society. Finally, this group puts 
the highest relative importance to the leisure domain.

Pattern $3(\mathrm{~N}=143,22.7 \%)$ : This pattern is identified as "work centred, high rights and duties, economic workers". They consider family an important life area and highly value the contacts at work. For them work is an opportunity to learn, rather than just time structuring. They define working as a self-directed activity accompanied by positive personal states.

Pattern $4(N=101,16.1 \%)$ Members are "non-work centred, economic workers with balanced moderate societal norms". They do not value work as basically interesting nor as an opportunity to learn. Therefore, the high emphasis on promotion seems to be mainly financial or power motivated. For this group religion and community are important life domains. They see working as serving society, but less as an activity one has to account for.

Pattern $5(\mathrm{~N}=65,10.3 \%)$ : Main characteristics are a high work centrality, a low expressive orientation, and little emphasis on the entitlement norm. Among the work goals they put main emphasis on the security of the job, while content, convenience of work hours, social contacts, learning opportunities, and the unpleasantness of the work activity, do only matter to a lesser degree. However, for these workers, status and prestige are valued working outcomes. Pattern 5 is labelled "highly work centred, low rights, low expressive workers".

\section{Stability of work meaning patterns during early career}

To examine whether the empirically identified work meaning patterns in our sample of young machine operators are relatively stable over a time period of two years during their early career, 
multiple discriminant analysis, with $\mathrm{T} 1$ work meaning indices as predictors and $\mathrm{T} 3$ patterns as groups, is performed on 591 cases. Table 2 gives the classification results.

The total percentage of correctly classified cases is 35.36 percent. Thus for one third of the sample we can predict the T3 pattern membership with the help of $\mathrm{T} 1$ work meaning indices correctly (bold printing in Table 2). For 64.64 percent of the respondents, the $\mathrm{T} 1$ indices predict membership of a different $\mathrm{T} 3$ pattern than their actual cluster. To evaluate this figure it has to be compared to the percentage correctly classified resulting when predicting T3 cluster membership using T3-indices, which is 81.56 percent. Comparing this two hit rates, reflects that work meanings undergo quite some changes during a two-year period.

The stability of work meaning patterns membership over time is highest for patterns 5 (highly work centred, low rights, low expressive workers), pattern 3 (work centred, high rights and duties, economic workers), and pattern 2 (non-work centred, high expressive and economic, non duty workers). The membershif of pattern 4 (non-work centred, economic workers with balanced moderate societal norms) and of pattern 1 (moderately work centred, non-economic, low rights workers) is rather changing over time. Both stable and changing work meaning patterns are characterized by a varying degree of work centrality; balanced or unbalanced work goals; and balanced (high or moderate) or unbalanced societal norms.

The major shift in overall pattern membership over time (see row and column totals Table 2) is away from pattern 5 (22\% to $10 \%)$ and towards pattern 1 (16\% to $34 \%)$ : from high towards 
moderate work centrality, and from rather high economic towards to non-economic work goals.

Insert Table 2 about here

\section{Correlates of work meaning patterns}

Differences between the five work meaning clusters in terms of four sample characteristics age, country, gender, and formal education were tested. Significant results were found for country (Chisq $=79.68 \mathrm{df}=28 \mathrm{p}=0.0000)$ and age $(\mathrm{F}=3.73 \mathrm{p}=0.005)$.

Generally all work meaning patterns occur in all countries. Thus work meaning patterns in early career are quite cross-national with respect to the eight European countries involved. Especially pattern 4 (non-work centred, economic workers with balanced moderate societal norms) is international in its occurrence and reflects some degree of European unity. However, European diversity is also present among the work meaning patterns in early career. Pattern 1 (moderately work centred, non-economic, low rights workers) occurs more in England; pattern 2 (non-work centred, high expressive and economic work goals, non-duty workers) in Belgium and Italy; pattern 3 (work centred, high rights and duties, economic workers) in Israel and Portugal; pattern 5 (highly work centred, low rights, low expressive workers) in England, Israel and Spain.

The youngest respondents are mainly in patterns 1 and 4 ; the somewhat older in patterns 2 and 5 ; the oldest in the work centred, high rights and duties, economic pattern 3. 
To explore the influence of the early work environment, socialization outcomes and behaviours on the formation of work meaning patterns, a multiple discriminant analysis - with $\mathrm{T} 1$ indicators of work environment, work socialization outcomes and behaviours as predictors, and the T3 work meaning patterns as groups - is performed on 615 cases.

The descriptive discriminant analysis yields one significant discriminant function (canonical correlation $=.24$, Wilks' lambda $=.88$, chisq $=77.38, \mathrm{df}=52, \mathrm{p}=.0128$ ). The rather low canonical correlation coefficient indicates that only a weak association exists between the work meaning patterns and the discriminant function.

For interpretation of the discriminant function (see Table 3), the discriminant function-predictor correlations are used because of their assumed greater stability (over the standardized coefficients) when there are possibly high intercorrelations between the predictors (Stevens, 1992); the standardized coefficients are only used to determine which of the predictors are redundant given that others are in the set. At the positive pole of the discriminant function are characteristics as the external labour market outlook, the organizational quality expressed in terms of job progress and experiences with co-workers, the person-environment (mis)match, the career enhancing behaviours and the effort put into the job as compared to co-workers. At the negative pole of the discriminant function are characteristics as the job properties "data" and "people", and the psychological wellbeing. Thus, for mere explorative purposes, the discriminant function may be interpreted as "societal-empioyer conditions and work behaviours" versus "occupational conditions and 
psychological well-being", or "broad work environment and early career behaviours" as opposed to "narrow work environment (the actual job properties) and early career outcomes".

Insert Table 3 about here

The location of the five work meaning patterns on the discriminant function is indicated by the group centroids. Examination of the group centroids in Table 3 shows negative centroids for patterns 2 and 4 , neutral for 3 , and positive for patterns 1 and 5 . However, the distances between the group centroids indicate again that the work meaning patterns are not very different on the conglomerate of $\mathrm{T} 1$ work environment, work socialization outcomes and behaviours.

Having this in mind, we still suggest that poor labour market, poor organization quality in terms of job progress and co-workers' experiences, mismatch person-environment, poor psychological well-being, poor enhancing behaviours, low effort level as compared to co-workers, and working in mainly people-and data-jobs (anti-typical for machine operators), seems to correspond with young workers who are non-work centred, stress economic work goals alone or in combination with expressive work goals, and express a low to moderate duty orientation on the societal norms (work meaning pattern 2 and 4).

On the other hand, positive labour market outlook, good organization quality, match personenvironment, good psychological well-being, good career enhancing behaviours, high effort level 
on the job, and absence of people-and data-jobs, relates to young workers with low rights orientation, moderate to high work centrality, and emphasis on either expressive or economic work goals (work meaning pattern 1 and 5).

Effect of work meaning patterns on work socialization outcomes and behaviours

Finally, we study the consequences of work meaning patterns in early career for subsequent work socialization behaviours and outcomes, while taking into account the relationship of the work meaning patterns with prior work outcomes and behaviours. Analyses of covariance are performed with work meaning patterns and country as factors, age and the T1 status of the dependent variable as covariates, and as dependent variables the T3 indicators for overall satisfaction, psychological well-being, career enhancing behaviours and effort level.

Table 4 illustrates the major results of the covariance analyses. For all four T3 consequences, their $\mathrm{T} 1$ status is the most powerful predictor. Country is a significant source of variance for satisfaction, psychological well-being and effort level. Work meaning patterns are significant predictors for career enhancing behaviours and for effort level.

Insert Table 4 about here

An additional multiple classification analysis for $\mathrm{T} 3$ career enhancing behaviours by work 
meaning patterns and country with $\mathrm{T} 1$ career enhancing behaviours and age as covariates is performed. The results in Table 5 indicate that after adjustment for the effect of $\mathrm{T} 1$ enhancing behaviours (see Table 4 for non-significant effect of country and age), the pattern means range from high to poor career enhancing behaviours at $\mathrm{T} 3$ for: patterns 3 and 5 (work centred, high rights alone or in combination with high duties, economic work goals); pattern 1 (moderate work centrality, non-economic, low rights); and patterns 2 and 4 (non-work centred, high economic work goals alone or in combination with expressive goals, and a low to moderate duty orientation).

An additional multiple classification analysis for $\mathrm{T} 3$ effort level by work meaning patterns and country with T1 effort level and age as covariates is performed. Table 5 illustrates that after adjustment for the effects of T1 effort level and country (see Table 4 for the non-significant effect of age), a very similar order of pattern means results as before. The pattern order arranged for effort level at T3 are from high to low: pattern 5, 3, 1, 2, 4 .

Insert Table 5 about here

Conclusions and Implications

Five cross-national work meaning patterns are identified for machine operators in their third year of labour market participation. The empirically derived work meaning patterns vary in degree of 
work centrality, in work goals' importance, and in orientation towards societal norms about working.

Work meaning patterns in early career seem more situation dependent than stable components of the "work personality". One third of the sample remain in the same work meaning pattern over a time period of two years, while two third change their membership. The major overall shift is from patterns with high to patterns characterized through moderate work centrality, and from rather high economic orientation to non-economic work goals.

Work meaning patterns (T3) are influenced by the respondents' age, country, and by work environment, work socialization outcomes and behaviours as assessed two years earlier (T1). Work meaning patterns affect $\mathrm{T} 3$ career enhancing strategies and effort, but so do also country membership and the prior (T1) status of these behaviours which were developed before the work entry.

Very briefly the main results of the study can be summarized as follows.

Poor work environment (poor occupational labour market, poor organization quality, working in anti-typical jobs), mismatch person-environment, poor psychological well-being, poor career enhancing strategies and low effort level, are characteristics for those respondents (about $34 \%$ of the sample), whose work meaning patterns reflect low work centrality, high economic or both high economic and expressive work goals and a low to moderate duty orientation on the societal norms (patterns 4 and 2). These respondents show the poorest work behaviour (effort level compared to co-workers and career enhancing strategies) at a later career stage. 


\section{References}

Aston, D., Maguire, M. \& Spilsbury, M. (1990). Restructuring the labour market. The implications for youth. London: The Macmillan Press Ltd.

Brief, A.P. (1991). MOW revisited : a brief commentary. In : Ruiz Quintanilla, S.A. (Ed.). Special Issue on Work centrality and related work meanings. The European Work and Organizational Psychologist, 1 (2-3), 176-181.

Council of the European Communities. Commission of the European Communities. (1992). Treaty on European Union. Luxembourg: Office for Official Publications of the European Communities. England, G.W. \& Ruiz Quintanilla, S.A. (1989). The meaning of working : major work meaning patterns in the national labour forces of Germany, Japan and the USA. In : B. Prasad (Ed.). Advances in International Comparative Management. (pp. 77-94). Greenwich, C.T.: JAI Press. England, G.W. \& Whitely, W. T. (1990). Cross-national meanings of working. In : Brief, A.P. and Nord, W. R. (Eds.). Meanings of occupational work. (pp. 65-106). Lexington, Massachusetts: Lexington Books.

Fine, S. A. \& Wiley, W.W. (1971). An introduction to functional job analysis. Kalamazoo MI: W.E. Upjohn Institute for Employment Research.

Gustafson, S.B. \& Magnusson, D. (1991). Female life careers : a pattern approach. Hillsdale NJ: Lawrence Erlbaum Associates 
Kanfer, R. (1992). Work motivation: new directions in theory and research. In: Cooper, C.L. \& Robertson, I.T. (Eds.). International Review of Industrial and Organizational Psychology 1992, $\underline{7}$ (pp. 1-53). London: John Wiley \& Sons.

Kanungo, R.N. (1991). Making meaning out of MOW research : a discussion. In : Ruiz Quintanilla, S.A. (Ed.). Special Issue on Work centrality and related work meanings. The European Work and Organizational Psychologist, 1 (2-3), 161-165.

Leibowitz, Z.B., Schlossberg, N.K. \& Shore, J.E. (1992). New employees: a career development challenge. In: Montross, D.H. \& Shinkman, C.J. (Eds.). Career development: theory and practice. (pp. 137-161). Springfield Illinois: Thomas Publisher.

MOW International Research Team. (1987). The meaning of working. London: Academic Press. Nord, W.R., Brief, A.P., Atieh, J.M. \& Doherty, E.M. (1987). Work values and the conduct of organizational behaviour. In : Staw, B.M. and Cummings, L.L. (Eds.). Research in Organizational Behaviour. (pp. 1-42). Greenwich CN: JAI Press.

O'Brien, G.E. (1992). Changing meanings of working. In : Hartley, J.F. and Stephenson, G.M. (Eds.). Employment relations. The psychology of influence and control at work. (pp. 44-66). Oxford : Blackwell.

Ruiz Quintanilla, S.A. (1990). Major work meaning patterns toward a wholistic picture. In: Kleinbeck, U. et al (Eds.). Work Motivation. (pp. 257-272). Hillsdale NJ : Lawrence Erlbaum. 
Ruiz Quintanilla, S.A. (Ed.) (1991). Special Issue on Work centrality and related work meanings. The European Work and Organizational Psychologist. 1 (2-3).

Shapira, Z. \& Griffith, T.L. (1990). Comparing the work values of engineers with managers, production, and clerical workers : a multivariate analysis. Journal of Organizational Behaviour. 11, 281-292.

Stevens, J. (1992). Applied multivariate statistics for the social sciences. Hillsdale NJ: Lawrence Erlbaum.

Ward, J. (1963). Hierarchical grouping to optimize an objective function. Journal of the American Statistical Association, 58, 236-244.

Wishart, D. (1987). Clustan User Manual. Edinburgh, Computing Laboratory, University of St. Andrews.

WOSY International Research Group. (1989a). Socializacion laboral del joven: Un estudio transnacional (Work Socialization of Youth: a cross-national study). Papeles del Psicologo, $39 / 40,32-35$.

WOSY International Research Group. (1989b). Interview schedule of the Work Socialization of Youth - Study. (Report no.1). University Gent Belgium. Department of Sociopsychology of Work and Organization.

WOSY International Research Group. (1992). Work socialization of youth. International Review of Social Psychology, 5 (1). 


\section{Footnotes}

1 Authors' names in alphabetic order. Requests for reprints can be sent to either author.

2 The authors like to thank George W. England and two anonymous reviewers for comments on an earlier draft of this manuscript. 


\section{Table 1}

Work meaning clusters (T3) in terms of work meaning indices (T3) $(\mathrm{N}=629)$

\begin{tabular}{|c|c|c|c|c|c|c|c|}
\hline Index (T3) & & $\begin{array}{l}\text { Cluster } 1 \\
\text { (T3) }\end{array}$ & $\begin{array}{l}\text { Cluster } 2 \\
\text { (T3) }\end{array}$ & $\begin{array}{l}\text { Cluster } 3 \\
\text { (T3) }\end{array}$ & Cluster 4 (T3) & Cluster 5 (T3) & Overall (T3) \\
\hline Work centrality & $\mathbf{M}$ & 6.6507 & 4.9099 & 7.3077 & 5.1782 & 8.3385 & 6.4308 \\
\hline scale $2-10$ & $\mathrm{SD}$ & 1.1298 & 1.5583 & 1.1398 & 1.2992 & 0.9727 & 1.6541 \\
\hline Obligations & $\mathrm{M}$ & 2.7990 & 2.3814 & 3.3170 & 2.7756 & 3.0461 & 2.8648 \\
\hline scale $1-4$ & $\mathrm{SD}$ & 0.3687 & 0.4514 & 0.3636 & 0.3863 & 0.4405 & 0.4981 \\
\hline Entitlements & $\mathbf{M}$ & 3.1017 & 3.4250 & 3.6381 & 3.2822 & 3.0923 & 3.3087 \\
\hline scale $1-4$ & $\mathrm{SD}$ & 0.3847 & 0.4187 & 0.2512 & 0.3156 & 0.2522 & 0.4033 \\
\hline Expressive work goals & $\mathbf{M}$ & 10.1483 & 11.2282 & 10.1398 & 7.4818 & 7.4102 & 9.6254 \\
\hline scale $1-15$ & SD & 2.0719 & 1.4943 & 2.0600 & 2.1683 & 1.9596 & 2.4025 \\
\hline Economic work goals & $\mathbf{M}$ & 9.6698 & 11.5375 & 11.6946 & 11.9174 & 11.7282 & 11.0328 \\
\hline scale $1-15$ & $\mathrm{SD}$ & 2.0192 & 1.9309 & 1.8534 & 1.3951 & 0.4405 & 2.0753 \\
\hline
\end{tabular}


Table 2

Work meaning patterns (T3) as predicted by work meaning indices (T1) $(\mathrm{N}=591)$

Predicted T3 group membership based on T1 indices (\%)

\begin{tabular}{lllll}
\hline 1 & 2 & 3 & 4 & 5
\end{tabular}

T3 work meaning pattern

$\%$ cases

15.7

21.5

25.0

15.9

21.8

\begin{tabular}{|c|c|c|c|c|c|c|}
\hline 1 Moderately work-centred, non-economic, low rights workers & 34.0 & 20.4 & 21.4 & 19.4 & 15.4 & 23.4 \\
\hline $\begin{array}{l}2 \text { Non-work centred, high expressive and economic, non duty } \\
\text { workers }\end{array}$ & 17.6 & 12.5 & 44.2 & 17.3 & 15.4 & 10.6 \\
\hline 3 Work centred, high rights and duties, economic workers & 22.3 & 11.4 & 12.1 & 49.2 & 9.8 & 17.4 \\
\hline 4 Non-work centred, economic workers with moderate societal norms & 16.1 & 15.8 & 21.1 & 5.8 & 28.4 & 18.9 \\
\hline 5 Highly work centred, low expressive oriented, low rights workers & 10.0 & 15.3 & 3.4 & 18.6 & 11.9 & 50.8 \\
\hline
\end{tabular}


Table 3

Discrimination of work meaning patterns (T3) on work environment, outcomes, behaviours (T1) $(N=615)$

\begin{tabular}{|c|c|c|c|c|}
\hline \multicolumn{3}{|c|}{ Characteristic with standardized coefficient (T1) } & $\begin{array}{l}\text { Correlation discriminant function- } \\
\text { predictor }\end{array}$ & \multirow{2}{*}{$\frac{\text { Pattern centroid (T3) }}{2 \text { Non-work centred, high }}$} \\
\hline Environment: & Labour market outlook & .30 & .34 & \\
\hline & Org. quality job progress & .24 & .45 & expressive \& economic, \\
\hline & Org. quality co-workers experiences & .45 & .55 & non-duty workers $\quad-.42$ \\
\hline & Job properties data & -.33 & -.38 & 4 Non-work centred, economic, \\
\hline & Job properties people & -.23 & -.34 & with moderate socictal norms -.15 \\
\hline & Job properties things & .06 & -.11 & \\
\hline \multirow[t]{5}{*}{ Outcomes: } & Person-environment match & .28 & .42 & 3 Work centred, high rights \& \\
\hline & Role conflict & -.09 & -.21 & duties, economic workers -.03 \\
\hline & Role ambiguity & .14 & -.01 & \\
\hline & Psychological well-being & -.12 & -.24 & 1 Moderately work centred, non- \\
\hline & Satisfaction & -.35 & .02 & economic, low rights workers .23 \\
\hline \multirow[t]{2}{*}{ Behaviours: } & Career enhancing & .28 & .35 & 5 Highly work centred, low \\
\hline & Effort compared to co-workers & .34 & .25 & rights, low expressive workers .27 \\
\hline
\end{tabular}


Table 4

Consequences (T3) of work meaning patterns (T3) (Covariance analysis with pattern and country as factors and T1 status and age as covariates)

\begin{tabular}{|c|c|c|c|c|c|c|}
\hline Consequence (T3) & & Patterns (T3) & Country (T1) & Interaction & Prior status (T1) & Age (T1) \\
\hline Overall satisfaction & & $\mathrm{F}=2.082$ & $\mathrm{~F}=18.439$ & $\mathrm{~F}=1.044$ & $\mathrm{~F}=27.371$ & $F=0.055$ \\
\hline $\mathrm{R}^{2}=0.235$ & $N=489$ & $\mathrm{p}=0.082$ & $p=0.000$ & $p=0.408$ & $\mathrm{p}=0.000$ & $p=0.815$ \\
\hline Psychological well-being & & $F=1.474$ & $F=7.954$ & $F=1.588$ & $F=29.565$ & $F=1.695$ \\
\hline $\mathrm{R}^{2}=0.137$ & $N=536$ & $p=0.209$ & $p=0.000$ & $p=0.044$ & $\mathrm{p}=0.000$ & $p=0.194$ \\
\hline Enhancing behaviours & & $F=7.235$ & $F=1.587$ & $F=1.436$ & $F=51.794$ & $F=0.077$ \\
\hline $\mathrm{R}^{2}=0.159$ & $N=482$ & $\mathrm{p}=0.000$ & $p=0.149$ & $p=0.100$ & $\mathrm{p}=0.000$ & $\mathrm{p}=0.781$ \\
\hline Effort & & $F=4.178$ & $F=6.301$ & $F=1.238$ & $F=16.124$ & $F=0.330$ \\
\hline $\mathrm{R}^{2}=0.132$ & $N=473$ & $\mathrm{p}=0.002$ & $\mathrm{p}=0.000$ & $p=0.218$ & $\mathrm{p}=0.000$ & $p=0.566$ \\
\hline
\end{tabular}


Table 5

Multiple classification analysis of career enhancing behaviour (T3) and effort level (T3) by work meaning patterns (T3)

Deviation adjusted for

$\mathrm{N} \quad$ Unadjusted deviation from grand mean independents + covariates ${ }^{* 1}$

Results for $\mathrm{T} 3$ enhancing behaviours (grand mean $=2.98$ )

1: Moderately work-centred, non-economic, low rights

workers

158

2: Non-work centred, high expressive and economic,

non duty workers

3: Work-centred, high rights and duties, economic

workers

4: Non-work centred, economic workers with balanced

moderate societal norms

5: Highly work-centred, low expressive, low rights

$$
\text { workers }
$$


Deviation adjusted for

$\mathrm{N}$ Unadjusted deviation from grand mean independents + covariates $^{2}$

Results for $\mathrm{T} 3$ effort (grand mean $=3.33$ )

1: Moderately work-centred, non-economic, low rights

workers

2: Non-work centred, high expressive and economic, non

duty workers

3: Work centred, high rights and duties, economic

workers

4: Non-work centred, economic workers with balanced

moderate societal norms

workers

-2 Independent variables: work meaning pattern and country Covariates: effort level as compared to co-worker and age 